\title{
Local Circles in a Circular Economy - the Case of Smartphone Repair in Denmark
}

\author{
Henrik Riisgaard, Mette Mosgaard* and Kristina Overgaard Zacho
}

\begin{abstract}
Circular economy has gained increasing attention the last decade, and more often the main focus is on the large global circles addressing recycling of materials rather than the "inner circles" that address maintenance/repair and reuse. In this article we investigate one such inner circle ofthe circular economy namely repair of smartphones which extends the lifetime of products and adds to a local economy. Local repair of smartphones has increased in the resent years in Denmark. These loop-closing businesses not only extend the useful lifetime of smartphones; they also entail both environmental benefits and economic value creation. We map the extent ofthe repair sector and investigate the drivers and barriers for its emergence. The study builds on desk studies for identification of repair companiesand telephone interviews with 33 out of 90 identified companies. The mapping of the businessesshows that the repair of smartphones constitute viable business opportunities, and that the main driversarerelated to the economic business potentials as well as motivated entrepreneurs who spot a market potential.The study concludes that the local circular economy within smartphone repair is due to large consumer willingness-to-pay for repair and maintenance services, and this can extend the lifetime of the smartphones. There are some special characteristics that limit the possibility to apply the results directly to other product groups, but further analysis of how to facilitate repair shops within other product groups are interesting in order to facilitate the development of local circles in a circular economy not only in Denmark but also in other countries.
\end{abstract}

Keywords: Circular economy; Smartphone;Repair; Remanufacturing.

\section{Introduction}

The concept of the circular economy has gained increased attention from politicians, corporations and scientific communities during the last decade due to growing awareness of the limitations of the earth's resources. The main objective is to establish closed-loop material flows in the economy (Su, Heshmati, Geng, \& Yu, 2013) and constitutes an alternative model for production and consumption (Sauvé, Bernard, \& Sloan, 2015). This contrasts with the traditional linear economy where resources are used for production and consumption and the environment functions as a sink for waste (Andersen, 2007).

The European Commission adopted a new Circular Economy Package, which includes revised legislative proposals on waste to stimulate Europe's transition towards a circular economy. It is intended to foster sustainable economic growth and generate new jobs. (European Commission, 2015).

\footnotetext{
${ }^{1}$ Department of Development and Planning,Aalborg University, Skibbrogade 5, 1st floor, 9000 Aalborg, Denmark.

*Corresponding Author.
} 
The principles of the circular economy(Ellen MacArthur Foundation, 2011) follow the principles of waste hierarchy (EU Commission, 2008); waste prevention, maintenance and reuse are to be prioritized over material recycling because maintenance and reuse are less energy intensive than recycling.

With a few exceptions, the academic interest in circular economy has so far concerned the outer material loops (Ghisellini, Cialani, \& Ulgiati, 2015; Huang, Guo, \& Xu, 2009; Kahhat et al., 2008; H. Kang \& Schoenung, 2005)rather than extending the useful lifetime of products. A recently published review of circular economy showed that out of 155 papers few address the inner circles of $\mathrm{CE}$ and most of these from a macro level perspective(Ghisellini et al., 2015). One of the conclusions in the review paper is that CE is still at its early stages and that explains the focus on recycling rather than reuse(Ghisellini et al., 2015).

The Club of Rome have supported a study of the circular economy and the benefits for society, and their study shows that there is a great potential for national jobs and climate saving in a further developmentof the circular economy(Wijkman \& Skånberg, 2015). As an example, it is estimated that CE in Sweden can lead to more than 100.000 jobs(Wijkman \& Skånberg, 2015). Similar studies have been made by two British research groups showing that reuse, repair and recycling can create more than 200.000 jobs in UK, and 1.2 million jobs in Europe (Mitchell \& James, 2015).

It is discussed how reuse and repair can be supported when it comes to consumer electronics (Kahhat et al., 2008; H. Kang \& Schoenung, 2005). Ongondo (2013) shows that reuse of electronics, especially computers, by socio-economic enterpriseshave the potential to contribute to a closed-loop economy (Ongondo \& Williams, 2011; Ongondo, Williams, Dietrich, \& Carroll, 2013). The reality, however, is that a majority of product groups are not designed for a circular economy, and industry lack incentives to change product design and business models in accordance with circular economy principles (Rashid et al., 2013).

The useful lifetime can be extended through reuse, repair and remanufacturing. Reuse covers situations where the smartphone changes user but otherwise is used in its original form and purpose. Repair of smartphones covers operations where the product undergoes corrections of specified faults in order to return it to good working condition and cosmetic appearance(Defra, 2007). Remanufacturing involves collection, testing, repair if needed and upgrading of used phones for reselling.In the concept of the circular economyreuse and repair are principally to be prioritized before recycling where the endof-life smartphone is processed to recover the materials in it (see figure 1).

Circular economy is often a public good problem: the environmental impacts are a societal problem whereas the consumption of the goods are private (Sauvé et al., 2015). An interesting aspect related to the smartphones are that the private consumers can have an economic incentive to get the phones repaired and thereby reused, and thereby the private actions and societal problems goes hand in hand.(Sarath, Bonda, Mohanty, \& Nayak, 2015).

Quariguasi and Bloemhof (2012) showed that remanufacturing of mobile phones can be more eco-efficient, i.e. more environmentally friendly and more economically advantageous than manufacturing of new phones(Quariguasi \& Bloemhof, 2012). 
Smartphoneshave short lifespans and are replacedfrequently; the average lifetime is less than two years in most countries (Sarath et al., 2015). Given the high and increasing volumes, used smartphones constitute an increasing and complex fraction of electronic waste (Sarath et al., 2015). Hence, it is positive to extend their lifetime in order to save resources for producing new ones, and also reduce the amount of WEEE(Zacho, 2013).

Smartphones are fragile and break easily - in fact more than one in ten consumers experience shattered glass or other damages during a year (Politiken, 2012). Combined with new models continually entering the market, consumers are encouraged to replace their smartphones with high frequency. On average,a smartphone in Denmarkis used between 9-18 months before it is replaced with a new one (Rune, 2012).Consumers expect frequent technical updates and high replacement rates(Cox, Griffith, Giorgi, \& King, 2013).

Research shows that extending the useful lifetime of small electronics like smartphones can reduce environmental impacts from the life cycle phases of material extraction, production, distribution and end-of-life, i.e. if the extension of the product's life replaces a purchase of a new product(Sarath et al., 2015). Unless newer models have significantly better energy efficiency performances, lifetime extension of products similar to smartphones are from an environmental perspective desirable(Prakash, Liu, Schischke, \& Stobbe, 2012; Quariguasi \& Bloemhof, 2012). In this article, we explore the local circles of repair of smartphones in Denmark to see what drives these inner circles, who seem to be more environmental friendly than e.g. recycling.

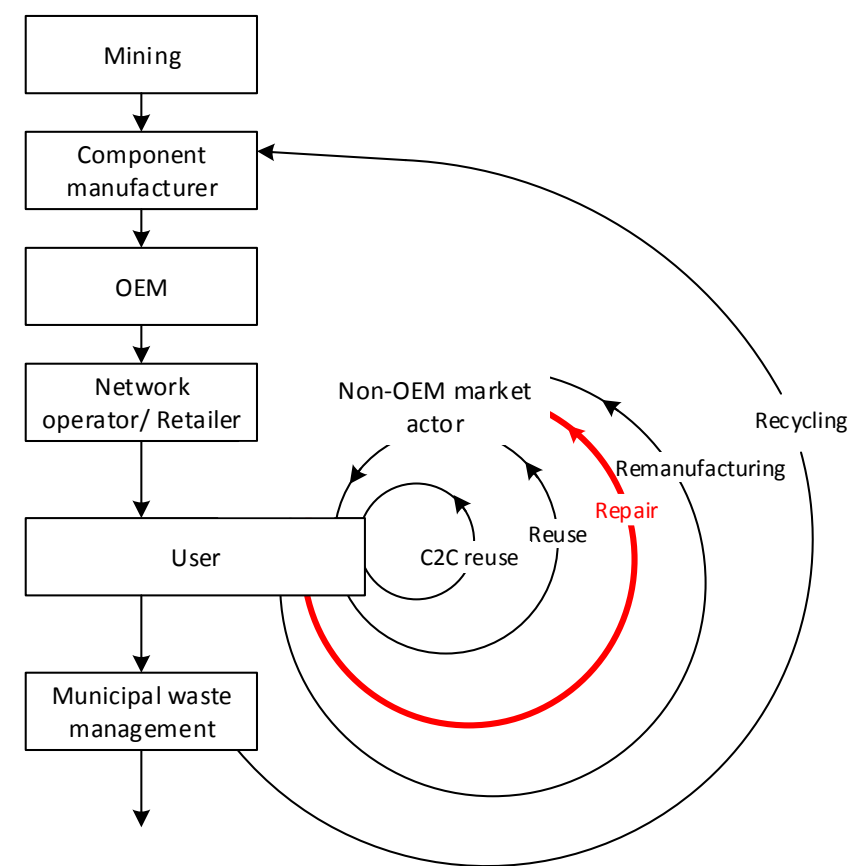

Figure 1: Illustration of circular economy, repair is marked in red. Inspired by (Ellen MacArthur Foundation, 2011). 
The market actors who repair smartphones provide services related to smartphones, which may retain the smartphones longer in use thereby potentially improving the resource efficiency, but also support the local economy, which was one of the intentional ideas of a circular economy(Ghisellini et al., 2015; Stahel, 1997; Stahel, 1982).

This article presents acountry-wide study of the market for repaired smartphones in Denmark. The purpose of the study is two-fold:To analyse the current drivers and barriers for actors whorepair smartphones and to suggest how to facilitate this repair market. Thereby the study adds to the early understanding how the inner circles in acircular economy is developing in Denmark.

\section{Methods}

The first step in the data collection is mapping the smartphone repair businesses in Denmark. The mapping is conducted as internet search using the words (in Danish) "smartphone repair", "iPhone repair". The reason that identification of companies for smartphone repair was conducted on the internet through common search engines (google)was that this would be the obvious choice for consumers to encounter the smartphone repair market. The online search was continued until no new results appeared and 90 businesses were identified.

Following this, the companies' websites and the Danish national Business Register (CVR) provided more information about the companies and this information was aggregated.The mapping provides an overview of the sector as of end of 2015. From this outset, characterization and categorization of the companies in the sector was made. They were categorized according to, business model (Business-to-business and businessto-consumer), size (number of employees), and their main service/products.

The third step in the data collection was a series of interviews with the company managers. The 90 identified business were contacted and 36 agreed to participate in telephoneinterviews. The 36 interviews each lasted on average 30 minutes each.

The interviews addressed the following themes

- Background information of company (development in size the last three years, year of establishment, online vs. physical shop etc.)

- $\quad$ Why the company was established

- $\quad$ Offered services and products

- $\quad$ Changes in the offered services the last three years

- What they perceive to be their "niche" in the market

- $\quad$ Development within the repair market

- $\quad$ Repair with new vs. reused parts

- $\quad$ Drivers and barriers on the market

- $\quad$ Private vs. B2B costumers 


\section{- $\quad$ Educational background}

The interviews were recorded and notes transcribed into a table that was classified into different themes related to the aim of the study. After this, the notes were analysed by reading them through, identifying trends and coding according to these trends. This approach is suitable to identify patterns in the results (Denzin \& Lincoln, 2005).

After identifying the drivers and barriers and developing the suggestions for facilitating the market, the suggestions was discussed with managers of two repair shops, in order to secure the validity of the findings.

There might be a build-in bias in who chooses to participate in interviews(Denzin \& Lincoln, 2005). By including 36 out of 90 potential respondents we are however quite confident that the bias does not influence the conclusions significantly. We have checked for some biases, and the bigger the companies are the more willing they are to participate. A similar conclusion can be drawn in relation to the "age" of the companies, the longer they have been on the market the more willing they are to participate. We have, however, several new and also one-man companies included.

One limitation of studies based on interviews is the generalizability. In order to assess the possibility for generalization to other sectors or companies, it is important to compare with previous findings, thus increasing the possibilities for identifying relevant findings. Another limitation relates to generalizability beyond the specific, which is explored(Flyvbjerg, 2001). We have chosen the smartphone repair market as it is anextreme case that is chosen to obtain information on an unusual case which is especially good (Flyvbjerg, 2001). What makes this case especially good in a repair sense is that the smartphones are expensive and that the users are willing to invest in repair instead of buying a new phone. The results can therefore only be generalized directly into other similar products like Tablets, but might also inspire for discussions of the possibility for establishing repair market for other product groups.

\section{Results}

In the following an introduction to the smartphone market is given, as it shows the market conditions that influences the repair business of smartphones. We show that the repair business is growing fast and analyze what drives this business.

\subsection{The smartphone repair market in Denmark}

New smartphones are primarily sold by retailers managed by network operators. Network operators subsidize smartphones through binding subscription periods for typically six, twelve or 24 months. The initial price of a new smartphone is high compared to other electronic devises, and the newest high-end models cost up to 1,000 $€$. 
When buying the phone with a subscription at a network operator, the price can be reduced and paid on credit as monthly subscription costs. This business model ensures high revenues for both the network operator and the smartphone producer, because it contributes to higher substitution frequency of phones as they are perceived to be affordable for more people. Unfortunately, this business model also leads to high resource consumption and environmental impacts (Boons \& Lüdeke-Freund, 2013).

The conventional way to get a smartphone repaired is through the network operator shop or the retailer. By the time of purchase, a law-required, two-year warranty on the product is provided(Directive 1999/44/EC). This implies the right to repair, if the phone has defects, but it does not cover self-inflicted damages. Self-inflicted damages can be repaired through the retailer, but the retailers do not repair the telephone in the individual stores, and due to the transportation the repair often takes several days, sometimes weeks (Politiken, 2012).

\subsubsection{Overview of local market actors in Denmark}

In 2010-2015a new type of companies emerged on the Danish market, namely companies making businesses on repair and selling used smartphones in Denmark. In total 90 companies with various degrees of engagement in smartphone reuse, repair and remanufacturingare identified in this study (excluding traditional retailers and network operators selling new smartphones).

The repair businesses constitute the largest share of companies in the sector; Of the 36 companies that participated in the interviews, 25 have smartphone repair as their key activity. The vast majority of the companies in the repair-category has emerged within the last four years, or has within the last four years expanded from other it-services to provide repair of smartphones additionally.

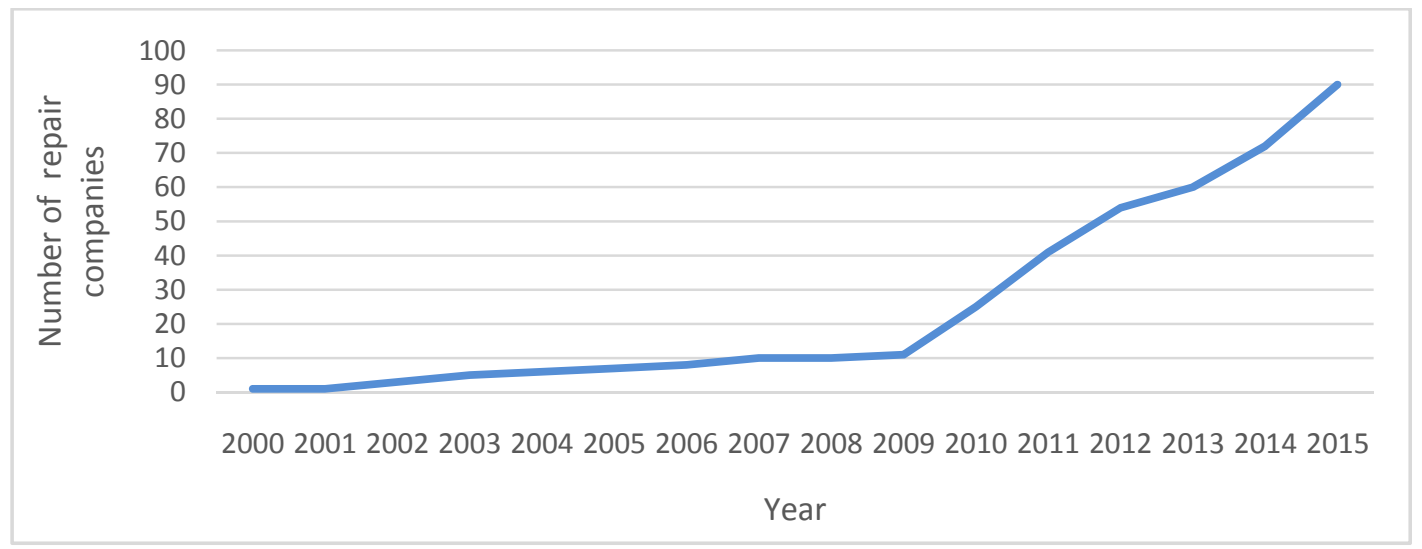

Figure 2, Number of smartphone repair companies in Denmark 
As illustrated in figure 2, the number of smartphone repair companies have increased rapidly since 2009. 28 of the companies are registered as one-man businesses. Of the 36 who participated in the interviews, 5 are one-man businesses and the rest have between 2 and 32 employees, with an average of 5 employees. Only 2 businesses have more than 10 employees. The one-man enterprises are primarily engaged in business to consumer (B2C) relations, and some only function on part-time basis. Besides two, all the larger repair shops all serve private consumers, but almost $50 \%$ of them have on-going service contractswith companies, schools and municipalities as a part of their business model.

Do-it-yourself (DIY) repair shops were also found. However, only 3 companies were identified with a business based on supplying smartphone spare parts and providing guiding videos on how to substitute and repair broken components. This finding, however, might underestimate the volume of a repairbusiness niche as such businesses could have more international platforms without representation in Denmark.

\subsection{Drivers and barriers for the emergence of local circular smartphone businesses}

By reading through the interview transcripts the main drivers and barriers for local circular actors in the repair sector is identified as: Economic incentives; traditional repair through retailers are slow and expensive; technical know-how among employees; consumer perceptions and practices and finally legal impediments for the repair. These are elaborated in the following. The main driver is demand, and the drivers falls under this category but is specified in the following.

\subsubsection{Economic incentives}

Several of the interviewed in the repair shops (mostly managers and floor-level employees) explain that repair of smartphones is a feasible business with many costumers. Some of them have switched from other services to repair of smartphones due to the demand. More than half of them explain that the number of phones they repair is still increasing. A few, however, say that the market have stagnated maybe due to the increasing number of repair shops. Only 12 of the companies are willing to tell how many smartphones they actually repair, and that is on average 5-10 a day pr. employee. That being said most of them also perform other services besides repair of smartphones.

High labour costs in Western Europe have generally made repair and remanufacturing unable to compete with cheap new products(Center for Reuse and Recycling, 2013). Nevertheless,smartphones repair has become a viable business due to the high prices of new products.The types of repair the companies offer differ slightly ranging from replacement of front (the most common defect) to major operations. Most repairs have warranty periods of up to two years equal to that of a new smartphones, this is due to EU legislation about consumer protection (European Union (EU), 2003). 


\subsubsection{Local repair is cheap and fast}

The increased repair activities arerooted in the current price structures and service setups of network operators and retailers. Repair of a smartphone through the network operator/retailer is both time consuming (one to three weeks), expensive $(200-320 €$ ) and the retailer does not always lend the consumer a phone during the repair. The retailers and network operators thus seem to have done very little to optimize the repair service, and this is supported in the interviews where time is one of the main service factors of importance. Moreover, smartphones are fragile and break easily. According to the interviewees, exchanging a shattered front may not take more than half an hour, thus the hourly working pay is high considering the low cost of components (approximately13 Euros for a grade A front).The respondents explain that they differentiate themselves by being either trustworthy, cheap or having a very fast service.

One of the shops have expanded the concept with an emergency "ambulance service" where they have success with repairing smartphones and other equipment wherever the costumer prefers. This is obviously an expensive solution, but fast and flexible,which is of interest to some customers. This shows that service is also important, not just price.

Another driver for repair of smartphones, even if it is expensive, is that by repairing an existing smartphone the user additionally saves time on the needed customization of apps. The interviewees indicate that the personal assistance and the limited need for reconfiguring the smartphones are important for the choice of repair service.

\subsubsection{Technical knowledge is needed to repair the smartphone}

The materials, components, joining and fastening methodsin the phone affects the fragility of the phones and determines the ease with which they can be repaired and upgraded. The consequence is that the product is not in use for as long as the potential lifetime. This creates a potential for the specialised repair business, whopossess the technical knowledge and thereby have the possibility to expand the lifetime of the products. Most of the employees in the repair shops have a technical education either as engineers or as technicians, but they still explain that they are "self -taught" for the repair business, as the smartphones changes all the time. A minority of the employees have either no education or have only participated in more short-term courses on repairing electronics. Those not educated as technicians are however very interested in electronics and explain that they are self-taught.

Several of the respondents explained that smartphones demand special knowledge and tools to be repaired since components and constructions differ from brand to brand; they are also different from model to model of the same brand. To disassemble smartphones, different tools are required for different phones, even of the same brand.

\subsubsection{Difficulties in getting spare parts}

More than half of the respondents say that a main barrier for their repairbusiness is getting the original spare parts. Only a few of them are certified by the OEM's to repair phones. Therefore, some of them do not use original parts for the repair, and they 
explain that it has become more difficult to get spare parts recently due to restrictions in trade with China.In general, the repairshops would like to use original spare parts but sometimes it is not a possibility.

The consumers can, most often, not see the difference between an original and a nonoriginal spare part, but according to the respondents, it might influence the durability of the repair.

Another obstacle for the repair is that some smartphones are very difficult to repair (e.g. they are glued together).Several of the respondents mention the same brands as difficult to repair.

\subsubsection{Consumer perceptions and practices}

The respondents from the interviews explain the importance of having a physical shop where the smartphones are repaired, because this enhances consumer trust. When consumers send a broken phone to an internet-based company for repair, they may find it too risky. The risk perception is not only related to fear of losing the phone but also to the risk of exposing and losing personal data on the phone. In contrast to an internetbased business, a repairer with a physical shop can inspire confidence through personal contact with the customer. The repair-shops mostly experience this with private costumers. There are however also seven of the shops that are only online-based and they are very small with 1-2 employees.

Two online shops have it as their main service to provide information and comparisons of repair-shops for the costumers; thereby providing consumers a more transparent market. Their rating service is popular and that shows the importance of trust for the consumers.

\subsubsection{Legal impediments}

The difficulty with obtaining original components for repairing smartphones is a barrier for the repair companies. Nevertheless, only four of 36 companies reported using components from used phones, whereas the rest chose to use the lower quality grade A components. Only one company was identified as offering differentiated prices depending on which type of components they used for the repair. In their business model, consumers can choose repair with original, un-original/copied or used components, where the prices on the latter two are lower than the price on repair with original components. Moreover, the company only provides a three months warranty period for B2B customers and only on the repaired parts of the phone. This is not legal in trade with private consumers, but in B2B service contracts it is fully legal.

Even though it is both cheaper and more environmentally friendly, the reasons that so few companies chose to use used components for repair is related to regulatory aspects and uncertainty of the long term effects of such practice. According to the European consumer legislation(European Union (EU), 2003)repair companies are required to provide a warranty period equivalent to that of new products (two years). Hence, the 
companies cannot offer repair with the use of used parts and components to the customers for a lower price and shorter warranty periods. Use of used components for repair entails increased uncertainty for the companies because it is uncertain how the used components will affect the long term performance of the smartphone. For instance, one respondent explains that defects caused by moisture or blows may not occur instantly but cause failures later. This uncertainty combined with the two year warranty periods may quite possibly be what constrains the companies from using used components for repair.

\section{Summary of results}

In table 2 a summary of the results are provided.

\begin{tabular}{|c|c|}
\hline Drivers & Main arguments \\
\hline Economic incentives & $\begin{array}{l}\text { There is a market demand } \\
\text { - The demands is coupled to an } \\
\text { expensive service }\end{array}$ \\
\hline Local repair gives a better service & $\begin{array}{l}\text { - Local repair is cheaper than the } \\
\text { "official" alternative through the retailers } \\
\text { - Local repair is fast } \\
\text { - } \\
\text { the person that you trust your smartphone to } \\
\text { (and get customized information). }\end{array}$ \\
\hline Technical knowledge is needed for the repair & $\begin{array}{l}\text { - The costumers cannot repair the } \\
\text { phone themselves } \\
\text { - People with technical competences } \\
\text { have an advantage. }\end{array}$ \\
\hline $\begin{array}{l}\text { Barriers } \\
\text { Difficulties in getting spare parts }\end{array}$ & $\begin{array}{l}\text { - It is difficult to get original spare parts } \\
\text { - } \quad \text { Used spare parts are often not } \\
\text { available } \\
\text { - } \quad \text { Non-original spare parts can be of a } \\
\text { lower quality and is sometimes difficult to get. }\end{array}$ \\
\hline Legal impediments & $\begin{array}{l}\text { - A legally determined long warranty } \\
\text { period makes it non-favourable to use used } \\
\text { parts for the repair. }\end{array}$ \\
\hline
\end{tabular}

Table 1, barriers and drivers for locally repairing smartphones in Denmark

The main drivers are coupled to the market demand due to a better service provided by the local repair shops, whereas the main barriers relate to the supply of spare parts and the legal impediments on the market. 


\section{Discussion}

Though repair activities contribute to resource efficiency and a more sustainable consumption and production of smartphones, the smartphonerepair companies investigated in this study have not emerged as a response to a green agenda. The same can on the other handalso be said about businesses in the bigger (outer) circles of the circular economy such as recycling; the companies engage in recycling activities because of either a regulatory agenda or an economic agenda(Sarath et al., 2015). They have emerged because there were opportunities for capturing economic value and making viable business.Circular economy is a framework for understanding the circles not for shaping them.

One of the drivers identified was consumer trust and confidence, and the importance of personal contact. Another important issue is the trust between the costumer and these relative new repair-shops, where the consumers actively look on homepages to see previous ratings of the repairs being done.In order to purchase the repair service, trust is required. This issue has been addressed by the British Department of Business, Innovation and Skills, who in collaboration with industry partners has developed the PAS 141:2011 protocol for mobile phones(WRAP, 2012). This is an example of an initiative aimed at supporting the repair and reuse businesses. The PAS 141 is intended to ensure some degree of certainty that the phone has been properly tested and repaired and that it functions.

There may be un-utilized potential in using components from used smartphones. The use of used components for repair can reduce environmental impacts from production of components and waste, and reduce costs for spare parts. A Chinese study assessed waste mobile phone components, and the LCA and LCC results showed that the reusability is high, which means that reuse is better than simple material recovery, both from an environmental and cost-benefit view(Lu et al., 2014).

It is legal to use used components, but since it is not known how it will affect the long term quality of a repaired/remanufactured smartphones, the companies are reluctant to provide the law enforced two year warranty(European Union (EU), 2003).

One important element of a product-service system is that it "delivers more value to the consumer than just the functionalities"(Roy \& Baxter, 2009). The repair shops have the potential to do that, and they already do it to some extent. Apart from repair, they offer services such as help and guidance on how to achieve maximum value of the smartphone. As one of the respondents describes in the interview:

"We experience increased demand for a service related to the software. People find it difficult to use, and they experience difficulties with integrating the facilities (email, contacts, Facebook and other social media). Here, we provide a service where we assist customers in relation to the user-friendliness and useroptimization of their phone". 
The new repair shops have the opportunity to engage in a new kind of relationship with the users, where they, in addition to repair, provide services, which optimizes the consumers' use of the phone, and thus the users' experienced value of the product. The extended service may also contribute to lifetime extension of the smartphones, because user satisfaction with the product can be increased when the functionalities of the phone are organized in a way that meets the individual needs. This corresponds with Kang and Wimmer's identified key factors for new product-service systems;optimized use of the products, customized solutions for each user and emotional satisfaction(M. Kang \& Wimmer, 2008).

Businesses engaged in repair depend on demands from consumers, as the consumers are not only recipients of products, but also of services. More importantly, the consumers constitute distribution channels and are thus possible suppliers of old products and components for the repair andremanufacturing of new products.

Being a large consumer of smartphones, public authorities have the ability to significantly affect the market. Public authorities can also support transition towards a resource efficient economyas an on-going service relationship could contribute to lifetime extension of the smartphones. They have the power to affect the repair market by requiring the use of the PAS 141:2011 protocol in the contracts with tenders (repair companies). One of the milestones of the European Commission's Flagship for a resource efficient Europe is development of incentives and tools for private and public consumers to choose the most resource efficient purchase (European Commission, 2011), and here the PAS 141:2011 protocol could be such a tool to support the implementation of green public procurement of resource efficient smartphones and services related to these.

\section{Conclusions}

Circular economy often address the large, outer loops of waste and materials across sectors and domains. In this study, we analyze how the large, international circles addressing recycling of materials from smartphones are supplemented with local repair circles, and thereby look into one of the areas that have received less attention in circular economy discussion the later years (Ghisellini et al., 2015).

This study shows that circular businesses already exist at a local level. 90 Danish companies are making a business out of repairing smartphones,but theydid not emerge as a response to a sustainability agenda. Yet, they contribute to a more sustainable consumption of smartphones by indirectly reducing the environmental impacts from production of new smartphones and prevent waste generation. Retaining the circular business activities locally can influence local economy positively, which would not be the case when the large global players control the remanufacturing, as suggested by Ellen MacArthur foundation.

The fact that the smartphones have high purchasing costs make them feasible to repair and reuse and there is a market opportunity which the actors can explore. The main drivers for these businesses are demand and the economic potential. It is a market with 
many customers who are willing to pay for a local service. The traditional repair of smartphones through retailers are expensive and time consuming, and that the consumers do not like to hand over their personal information stored on the phone to someone that they have not met. The service of the local repair shops are on the other hand cheap, fast and physically present where the customer needs them. The repair shops also benefit from the fact that smartphone repair is often too complex to be managed by the individual consumer, and most of the employees in the repair shops have a technical education (engineer, technicians and similar). The main barriers are the legal barriers due to warranty periods but also the availability of spare part for the repair especially original parts.

The repair business of smartphones in Denmark differs from other types of electronic equipment due to the business models where the consumers have a binding subscription period when they purchase their phones. This means that they have an economic incentive for keeping (and repairing if necessary) the phone for as long as the subscription period run.

The possibilities for supporting a further development of a local repairmarket in Denmark relates to standards for testing the repaired phones. This makes it possible for both the customer and the repair shop to specify the quality of the repair service. It might be difficult to influence the market for spare parts, but the availability of original used parts might be relevant to support e.g. by strengthening the reverse logistics.

The semi- qualitative approach in this article does not allow for quantitative conclusions of the environmental benefits of a local circular economy of smartphones, but the sector is growing and the local repair of smartphones founds more than 200 jobs in Denmark alone.

Doing interviews with the employees (often the managers) in the repair shops have revealed insights into what drives their business and the obstacles they face, but also their strategies for meeting a demand on the market they operate in. These insights would not be revealed by e.g. a questionnaire or another quantitative method. Related to the aim of this study, namely to analyse the current drivers and barriers for actors that repair smartphones and to suggest how to facilitate this repair market, the method have been appropriate. It could however be supplemented with discussions of the suggestions with the market actors, which have only been done in two cases.

The inner circles of the circular economy such as reuse and repair will be very dependent on the behavior of the consumers and the market situation in the specific cases. This influences the possibilities for generalizing. There are, nonetheless, some findings in this article which might be applicable for other areas as well; the consumers are interested in local repair of their goods, especially if they can save time or money, and service is important in that regard. The possibilities for local repair shops are dependent on the availability of spare parts, and the OEM's willingness to sell the spare parts to noncertified repair shops. 
Future research into the development of local circles within the circular economy is needed. Both to explore the environmental and economic potential, and to foster a development that follows the original thoughts of circular economy; namely to promote local cycles that lead to life extension of products and reduction in replacement rates of new products all over the world. It can be interesting to explore how the inner circles are developing within other product groups as well.

\section{Acknowledgement}

The researchers would like to thank The Danish Waste Association for financing the data collection and the initial data analysis.

\section{References}

Andersen, M. S. (2007). An introductory note on the environmental economics of the circular economy. Sustainability Science, 2(1), 133-140.

Boons, F., \& Lüdeke-Freund, F. (2013). Business models for sustainable innovation: State-of-theart and steps towards a research agenda. Journal of Cleaner Production, 45, 9-19.

Center for Reuse and Recycling. (2013). CRR. Retrieved from www.remanufacturing.org.uk

Cox, J., Griffith, S., Giorgi, S., \& King, G. (2013). Consumer understanding of product lifetimes. Resources, Conservation and Recycling, 79, 21-29.

Defra. (2007, An analysis of the spectrum of re-use. A component of the remanufacturing pilot, for defra, BREW programme. oakdene hollins ltd.

Denzin, N. K., \& Lincoln, Y. S. (2005). The sage handbook of qualitative research. London: Sage.

Ellen MacArthur Foundation. (2011). Ellen MacArthur foundation - rethink the future. Retrieved from http://www.ellenmacarthurfoundation.org/circular-economy

EU Commission. (2008). Directive 2008/98/EC of the european parliament and of the council of 19 november 2008 on waste and repealing certain directives (waste framework directive).LexUriServ.Do,

European Commission. (2011). Meddelelse fra kommissionen til europa-parlamentet, rådet, og det europaiske okonomiske og sociale udvalg og regionsudvalget. Koreplan til et resourceeffektivt europa. 0 .

European Commission. (2015). Circular economy strategy- closing the loop - an EU action plan for the circular economy. Retrieved from http://ec.europa.eu/environment/circulareconomy/index en.htm

European Union (EU),. (2003). Directive 2002/96/EC of the european parliament and of the council of 27 january 2003 on waste electrical and electronic equipment (WEEE). Official Journal of the European Union, 37, 24.

Flyvbjerg, B. (2001). Making social science matter: Why social inquiry fails and how it can succeed again. Cambridge: Cambridge university press.

Ghisellini, P., Cialani, C., \& Ulgiati, S. (2015). A review on circular economy: The expected transition to a balanced interplay of environmental and economic systems. Journal of Cleaner Production,

Huang, K., Guo, J., \& Xu, Z. (2009). Recycling of waste printed circuit boards: A review of current technologies and treatment status in china. Journal of Hazardous Materials, 164(2), $399-408$.

Kahhat, R., Kim, J., Xu, M., Allenby, B., Williams, E., \& Zhang, P. (2008). Exploring e-waste management systems in the united states. Resources, Conservation and Recycling, 52(7), 955964. 
Kang, H., \& Schoenung, J. M. (2005). Electronic waste recycling: A review of US infrastructure and technology options. Resources, Conservation and Recycling, 45(4), 368-400.

Kang, M., \& Wimmer, R. (2008). Product service systems as systemic cures for obese consumption and production. Journal of Cleaner Production, 16(11), 1146-1152.

Lu, B., Li, B., Wang, L., Yang, J., Liu, J., \& Wang, X. V. (2014). Reusability based on life cycle sustainability assessment: Case study on WEEE. Procedia CIRP, 15, 473-478.

Mitchell, P., \& James, K. (2015). ECONOMIC GROWTH POTENTLAL OF MORE CIRCULAR ECONOMIES. (). United Kingdom: WRAP.

Ongondo, F., \& Williams, I. (2011). Mobile phone collection, reuse and recycling in the UK. Waste Management, 31(6), 1307-1315.

Ongondo, F., Williams, I., Dietrich, J., \& Carroll, C. (2013). ICT reuse in socio-economic enterprises. Waste Management, 33(12), 2600-2606.

Politiken. (2012). Apple vildleder iPhone-kunder. politiken. 13. july 2012. Retrieved from http://politiken.dk/tjek/digitalt/ECE1689121/apple-vildleder-iphone-kunder/

Prakash, S., Liu, R., Schischke, K., \& Stobbe, P. L. (2012). Early replacement of notebooks considering environmental impacts. Electronics Goes Green 2012 (EGG), 2012, 1-8.

Quariguasi, F. J., \& Bloemhof, J. (2012). An analysis of the Eco-Efficiency of remanufactured personal computers and mobile phones. Production and Operations Management, 21(1), 101114.

Roy, R., \& Baxter, D. (2009). Product-service systems.

Rune, T. (2012). Vi salger den gamle iPhone for at kabe en ny. dr.dk. nyheder 25. sep. 2012 . Retrieved from http://www.dr.dk/Nyheder/Indland/2012/09/25/105602.htm

Sarath, P., Bonda, S., Mohanty, S., \& Nayak, S. K. (2015). Mobile phone waste management and recycling: Views and trends. $W$ aste Management, 46, 536-545.

Sauvé, S., Bernard, S., \& Sloan, P. (2015). Environmental sciences, sustainable development and circular economy: Alternative concepts for trans-disciplinary research. Environmental Development,

Stahel, W. R. (1997). The service economy: 'wealth without resource consumption'? Philosophical Transactions of the Royal Society of London.Series A: Mathematical, Physical and Engineering Sciences, 355(1728), 1309-1319.

Stahel, W. R. (1982). The product life factor. An Inquiry into the Nature of Sustainable Societies: The Role of the Private Sector (Series: 1982 Mitchell Prize Papers), NARC,

Su, B., Heshmati, A., Geng, Y., \& Yu, X. (2013). A review of the circular economy in china: Moving from rhetoric to implementation. Journal of Cleaner Production, 42, 215-227.

Wijkman, A., \& Skånberg, K. (2015). The circular economy and benefits for society swedish case study shows jobs and climate as clear winners. An Interim Report by the Club of Rome with Support from the MAVA Foundation and the Swedish Association of Recycling Industries,

WRAP. (2012). Mobile phone equipment - product protocol.. Retrieved from http://www.wrap.org.uk/sites/files/wrap/Mobile $\% 20$ phone $\% 20$ equipment $\% 20$ $\% 20$ product $\% 20$ protocols.pdf

Zacho, K. O. (2013). Barriers and opportunities for smartphone reuse and repair businesses . 16th Conference of the European Roundtable on Sustainable Consumption and Production, 